\title{
Identification of nuclear factor-KB inhibitors in the folk herb Rhizoma Menispermi via bioactivity-based ultra-performance liquid chromatography/quadrupole time-of-flight mass spectrometry analysis
}

Dan Sun, Mengge Zhou, Xuhui Ying, Binfeng Cheng, Yanqi Han, Yan Nie, Yuanyuan Hou* and Gang Bai

\begin{abstract}
Background: Rhizoma Menispermi (RM) is the dried root of Menispermum dauricum DC, which is traditionally used to treat swelling and pain for sore throat, enteritis and rheumatic arthralgia in the clinic, but its bioactive compounds remain unclear.

Methods: In this study, RM extract was administered orally to ICR mice followed by challenging with an intratracheal Pseudomonas aeruginosa suspension. Then mortality, histological features of lung, and inflammatory cytokines were evaluated. RM treatment significantly ameliorated Pseudomonas aeruginosa-induced acute lung inflammation and reduced levels of inflammatory mediators. To screen for potential anti-inflammatory constituents of the RM extract, a simple and rapid method based on ultra-performance liquid chromatography/quadrupole time-of-flight mass spectrometry (UPLC-Q/TOF MS) coupled with a luciferase reporter assay system to detect nuclear factor-KB (NF-KB) activity was established.

Results: Using this system, seven potential NF-KB inhibitors were detected, including sinomenine, norsinoacutin, $\mathrm{N}$-norsinoacutin- $\beta$-D-glucopyranoside, 6-O-methyl-laudanosoline-13-O-glucopyranoside, magnoflorine, laurifloline and dauricinoline. Furthermore, IL-6 and IL-8 assays confirmed the anti-inflammatory effects of these potential NF-KB inhibitors, in which norsinoacutin, 6-O-methyl-laudanosoline-13-O-glucopyranoside laurifloline, dauricinoline and $\mathrm{N}$-norsinoacutin- $\beta$-D-glucopyranoside were revealed as new NF-kB inhibitors.

Conclusion: This method of UPLC-Q/TOF coupled with the luciferase reporter assay system was initially applied to the study of RM and was demonstrated to represent a simple, rapid and practical approach to screen for anti-inflammatory compounds. This study provided useful results for further investigation on the anti-inflammatory mechanism of RM.
\end{abstract}

Keywords: Bioactive constituent identification, NF-kB inhibitor, UPLC/Q-TOF MS, Rhizoma Menispermi, Anti-inflammation

\footnotetext{
*Correspondence: houyy@nankai.edu.cn

State Key Laboratory of Medicinal Chemical Biology, College of Pharmacy and Tianjin Key Laboratory of Molecular Drug Research, Nankai University, Tianjin 300071, China
} 


\section{Background}

Lung inflammation occurs as a consequence of complex interactions between multiple cell types, cytokines, and mediators of the inflammatory network [1]. It can lead to cytokine production, vascular leakage, and neutrophil influx by activating the immune system, and the combined response of local immune cells mediated by cytokines, chemokines and adhesion molecules contributes to severe lung injury and mortality [2,3]. NF- $\mathrm{kB}$ (nuclear factor- $\mathrm{kB}$ ) is considered to play a central role in a variety of acute and chronic inflammatory diseases [4]. During inflammation, NF-kB cooperates with multiple upstream signaling pathways and other signaling molecules by regulating and activating the expression of multiple cytokines, chemokines and inflammatory mediators $[5,6]$. Active NF-kB can enter the nucleus to activate the transcription of TNF- $\alpha$ (Human tumor necrosis factor alpha), IL-6 (interleukin-6), IL-8 (interleukin-8) and other inflammatory factors, which can cause the repeated phosphorylation and degradation of $\mathrm{I}_{\kappa} \mathrm{B}$, leading the activation of $\mathrm{NF}-\mathrm{kB}$ and further increasing the expression of inflammatory cytokines $[7,8]$. Thus, $\mathrm{NF}-\mathrm{\kappa B}$ is a key transcription factor in the inflammatory response, and targeting NF- $\mathrm{kB}$ is increasingly recognized as a fascinating opportunity to develop novel therapeutics for inflammatory disorders.

It is difficult to target the desired lesions when treating inflammatory disorders using Western drugs, such as corticosteroids and non-steroidal anti-inflammatory drugs because inflammation involves many inflammatory mediators and pathways that lead to a wide range of physiological changes [9]. Recently, traditional Chinese medicine (TCM) has drawn more and more attention because of its multi-component characteristics, including the ability to affect multiple targets and levels of signaling pathways and their multiple mechanisms to mitigate inflammation [10]. A large number of mechanistic studies have been performed by experts worldwide that demonstrate the importance and necessity of investigating TCM.

Rhizoma Menispermi (RM) is a commonly used herbal drug in TCM that has been reported to be effective for clearing away heat, removing toxic material, dispelling wind and relieving pain, and RM is typically used to treat swelling and pain for sore throat, enteritis and rheumatic arthralgia in the clinic. The dried root of Menispermum dauricum DC (Menispermaceae) is the predominant source of RM [11]. The primary components of RM are alkaloids, which principally could be classified as morphinane and aporphine-type alkaloids [12-14]. Presently, the ingredients magnoflorine, acutumine, acutumidin, acutuminine and sinomenine have been extracted and separated from RM [15]. The anti-inflammatory effect of a water decoction of RM on mice has been reported [16,17]. Nevertheless, the therapeutic effect of RM on lung inflammation remains uninvestigated, and the bioactive components in RM remain unknown.
Identifying novel bioactive compounds from TCMs remains a challenge, although many of these compounds have been demonstrated to be effective based on modern pharmacological studies and clinical trials. Traditional methods based on the extraction and isolation of purified compounds to screen for bioactive compounds consume a great deal of time and sample. Therefore, a rapid and effective screening method is necessary. Ultra-performance liquid chromatography/ quadrupole time-of-flight mass spectrometry (UPLC/QTOFMS) is being widely applied to analyze and identify TCM components due to its high peak capacity, high resolution, greater speed of analysis, and the advantages of structural information derived from TOFMS (timeof-flight mass spectrometry) technology for accurate mass determination $[18,19]$. Our group has developed an approach combining UPLC/Q-TOF-MS with a luciferase reporter assay system to rapidly screen for inhibitors of NF- $\mathrm{B}$, which is a simple and effective strategy to rapidly screen for anti-inflammatory compounds in TCM preparations [20].

Pseudomonas aeruginosa is a ubiquitous opportunistic pathogen $[21,22]$. It is a gram-negative bacterium which causes various infections, especially in patients with compromised host defense mechanisms $[23,24]$. P. aeruginosa causes a remarkably higher mortality than other lung infection pathogens and has been categorized as one of the most pressing threats to the future of human health by the Infectious Diseases Society of America $[25,26]$. $P$. aeruginosa can colonize in airway epithelium with its surface appendages such as flagella and pili. And it produces toxins such as type III secretion protein, pyocyanin and LPS, and rapidly causes serious lung inflammation. A comprehensive reaction of immune cells such as macrophages, neutrophils, and lymphocytes mediated by cytokines and chemokines can also contribute to severe lung injury and mortality. It has been shown that inflammatory cytokines and chemokines such as TNF- $\alpha$, IL-1 $\beta$, IL-6, IL-8, and RANTES have deleterious effects in the progression and persistence of lung inflammation $[27,28]$.

In this study, the anti-inflammatory effect of RM on lung inflammation induced by the Pseudomonas aeruginosa PAK strain was investigated. The bioactive compounds were screened using UPLC-MS and NF-kB luciferase reporter system assays. This study could indicate the potential anti-inflammatory agents of RM and provide useful results for further investigation on the anti-inflammatory mechanism of RM at the molecular level.

\section{Methods}

\section{Chemicals and materials}

Strain PA68 was a clinical isolate from the sputum of a patient suffering from bronchiectasis [29]. HPLC-grade 
acetonitrile was purchased from Merck (Darmstadt, Germany). Deionized water was purified using a Milli-Q system (Millipore Laboratory, Bedford, MA, USA). RM, Lot No. 1208076931, was purchased from AnGuo Changan Limited Company (HeBei, China) and identified by Professor Tiejun Zhang from the Tianjin Institute of Pharmaceutical Research. Magnoflorine and sinomenine were purchased from Yifang S\&T (Tianjin, China). N-norsinoacutin- $\beta$-D-glucopyranoside, norsinoacutin, dauricinoline laurifloline and 6-O-methyl-laudanosoline-13-O-glucopyranoside, were isolated and purified from RM by our group, which were determined to be more than $98 \%$ pure based on HPLC. TNF- $\alpha$ was obtained from PeproTech (Rock Hill, NJ). Cefradine (Cef) capsules were purchased from Hainan Haili Pharmaceutical Co., Ltd (Hainan, China). Dexamethasone (Dex) was purchased from Sigma Chemical Co. (St. Louis, MO, USA). $\mathrm{CO}_{2}$ was purchased from Industrial Gas Distribution Co., Ltd., Tianjin hexagonal. Avertin was purchased from Kangkede Technology Co., Ltd (Tianjin, China). All reagents for cell culture were purchased from Gibco BRL Life Technologies (Rockville, MD, USA). Lipofectamine 2000 transfection reagent was obtained from Invitrogen (Carlsbad, CA, USA). All other reagents used in this study were of analytical grade.

\section{Animals}

ICR mice (male, 18-22 g) were purchased from the Experimental Animal Center of the National Institute for the Control of Pharmaceutical and Biological Products (Beijing, China). All Animals were housed in standard conditions with a normal diet under an ambient temperature of 23$26^{\circ} \mathrm{C}$ and $40 \%-65 \%$ relative humidity with a $12 \mathrm{~h}$ light/dark artificial light cycle.

\section{Ethics statement}

All experimental protocols carried out conformed to the Guide for the Care and Use of Laboratory Animal Care and Use in Research (Ministry of Health, Beijing, China), and were approved by the Animal Ethics Committee of Nankai University.

\section{Sample preparation}

RM powder (10 g) was added to 10 volumes of water and decoated for $1 \mathrm{~h}$. The decoction was filtered and then concentrated to a final concentration of $1 \mathrm{~g} / \mathrm{mL}$ (crude drug/decoction).

One gram of RM was lyophilized and sequentially extracted using $10 \mathrm{~mL}$ of petroleum ether, dichloromethane, ethyl acetate, $n$-butanol and distilled water. Each fraction was evaporated in vacuo. Then, the petroleum ether extract (PEE), dichloromethane extract (DME), ethyl acetate extract (EAE), n-butanol extract (BUE) and aqueous extract
(AQE) were obtained. The extracts were dissolved in a $0.1 \%$ DMSO solution and resuspended in cell-cultured medium for the luciferase activity assays.

The BUE fraction was dissolved in methanol and filtered using a $0.22 \mu \mathrm{m}$ filter prior to LC/MS analysis.

\section{$P$. aeruginosa PAK strain-induced acute lung infection mouse model}

An acute lung infection test was performed using the $P$. aeruginosa PAK strain-induced mouse model [21]. The mice were randomly separated into the following six groups: control group, model group; low, middle and high dose RM (RM-L, RM-M and RM-H) groups, and positive control (Cef) group. Each group consisted of 10 mice. All mice were treated with the $P$. aeruginosa PAK strain, except for the mice in the control group. The mice in the RM groups were intragastrically administered the appropriate dose $(1,3$ or 9 g crude drug $/ \mathrm{kg}$ ) for 7 consecutive days. The positive control and model group mice were administered Cef $(100 \mathrm{mg} / \mathrm{kg})$ and normal saline, respectively. The $P$. aeruginosa PAK strain was cultured in Luria-Bertani medium and resuspended in sterile PBS at a concentration of $10^{9}$ colony-forming units $/ \mathrm{mL}$. Prior to the challenge, the mice were anesthetized via intraperitoneal injection of avertin $(250 \mathrm{mg} / \mathrm{kg})$. The mice were then intratracheally challenged with $40 \mu \mathrm{L}$ of $P$. aeruginosa PAK. Whole blood and lung tissue samples were collected $24 \mathrm{~h}$ after stimulation. The lung tissue biopsies were fixed using $4 \%$ buffered formalin and embedded in paraffin for hematoxylin and eosin (HE) staining. For survival studies, the mice were observed regularly over the subsequent $1 \mathrm{~d}$ after challenged with PAK. Survival was monitored every $4 \mathrm{~h}$ and number of deaths in all the groups were recorded. After P. aeruginosa PAK infection, each mouse was given ad libitum access to food and water. Data was plotted on Kaplan Meir's survival curve using Prism 5.0 software (GraphPad software Inc., San Diego, CA, USA).

\section{Measurement of proinflammatory cytokines}

Commercially available enzyme-linked immunosorbent assay (ELISA) kits (Pierce/Endogen, Rockford, IL, USA) were used to measure the levels of IL- 6 , IL- 8 and TNF- $\alpha$ in serum. The absorbance at $450 \mathrm{~nm}$ of each of the samples was measured using a Bio-Rad Model 680 microplate reader. The levels of IL-6, IL- 8 , and TNF- $\alpha$ were determined based on standard curves and expressed as $\mathrm{pg} / \mathrm{mL}$. Similarly, the levels of IL-6 and IL- 8 in supernatant were measured via this method.

\section{Cell culture and transfection}

Human embryonic kidney (HEK) 293 cells were purchased from American Type Culture Collection (Rockville, MD, USA). HEK 293 cells were grown to confluence in 96-well 
plates at $37^{\circ} \mathrm{C}$ and $5 \% \mathrm{CO}_{2}$ in a humidified incubator using $\operatorname{DMEM}(\mathrm{H})$ medium supplemented with $10 \%$ fetal bovine serum.

HEK 293 cells were co-transfected with the NF- $\mathrm{kB}$ luciferase reporter plasmid PGL4.32 (Promega, WI, USA) and the Renilla luciferase reporter vector plasmid pRL-TK (Promega) at 100 and 9.6 ng per well, respectively. Transfection was performed for $24 \mathrm{~h}$ using Lipofectamine 2000 according to the manufacturer's instructions. The medium was replaced with fresh serum-free medium $24 \mathrm{~h}$ prior to experimentation. The cells were pretreated with the drug $1 \mathrm{~h}$ prior to TNF- $\alpha$ stimulation $(10 \mathrm{ng} / \mathrm{mL})$ for $6 \mathrm{~h}$.

\section{Dual-luciferase assay}

After the cells had been stimulated, HEK 293 cells were washed, lysed, and assayed for luciferase activity using a dual-luciferase reporter assay system (Promega) according to the manufacturer's instructions. The relative luciferase activity was calculated by normalizing the firefly luciferase activity against that of the internal control (Renilla luciferase).

\section{UPLC/Q-TOF MS analysis and sample preparation for activity assays}

A Waters Acquity UPLC system (Waters Co., USA) equipped with a photodiode array detector (DAD) and a Waters Q/TOF Premier Mass Spectrometer with an electrospray ionization system (Waters MS Technologies, Manchester, UK) were used for sample analysis. The data acquisition was supported by MassLynx V4.1 software (Waters Co., USA). The separations were performed using a Waters Acquity UPLC $\mathrm{BEH} \mathrm{C}_{18}$ column $(2.1 \mathrm{~mm} \times 100 \mathrm{~mm}, 1.7 \mu \mathrm{m})$ at $30^{\circ} \mathrm{C}$. The mobile phase was acetonitrile (A)/ water containing $1 \%$ formic acid (B) at a flow rate of $0.4 \mathrm{~mL} / \mathrm{min}$, and a gradient was performed as follows: $0-3 \mathrm{~min}$, A from $5 \%$ to $10 \%$; $3-$ $10 \mathrm{~min}$, A from $10 \%$ to $20 \%$; $10-14 \mathrm{~min}$, A from $20 \%$ to $50 \%$; $14-16 \mathrm{~min}$, A from $50 \%$ to $95 \%$. The compounds were detected via DAD scanning from $200 \mathrm{~nm}$ to $400 \mathrm{~nm}$. The sample injection volume for analysis was $5 \mu \mathrm{L}$. The ESI-MS spectra were acquired in the negative and positive ion modes. The conditions for ESI-MS analysis were as follows: the capillary voltage was set at $2.5 \mathrm{kV}$, the sample cone voltage was set at $30 \mathrm{~V}$, the desolvation gas flow rate was set at $600 \mathrm{~L} / \mathrm{h}$ at a desolvation temperature of $300^{\circ} \mathrm{C}$, the cone gas flow rate was set at $50 \mathrm{~L} / \mathrm{h}$, and the source temperature was $100^{\circ} \mathrm{C}$. The Q/ TOF Premier acquisition rate was $0.1 \mathrm{~s}$ with a $0.02 \mathrm{~s}$ inter-scan delay. The MS spectra are acquired from 50 to $1500 \mathrm{Da}$. Leucine-enkephalinamide acetate (LEA) was used as the lock mass (m/z 555.2931 in ESI + mode and 553.2775 in ESI- mode) at a concentration of $200 \mathrm{ng} / \mathrm{mL}$ and a flow rate of $0.2 \mu \mathrm{L} / \mathrm{min}$. MS/MS analysis was performed to calculate the mass fractions of the target ions.
For sample preparation, mass spectrometry was not performed, and the fractions were collected from the outlet of the DAD into a 96-deep-well plate every $0.5 \mathrm{~min}$. Then, the solvent was evaporated until dryness in a vacuum drying oven. The residues were dissolved in $100 \mu \mathrm{L}$ of cell culture medium for further bioactivity assays.

\section{Statistical analysis}

Statistical analysis was performed using SPSS software, and the data were expressed as the means \pm SEM. Multiple comparisons were performed using ANOVA followed by Bonferroni post hoc analysis. For single comparisons, significant differences between the means were determined using Student's $t$ test. $P<0.05$ was considered to be statistically significant.

\section{Results and discussion}

\section{Effect of RM on lung infection induced by the $P$. aeruginosa PAK strain}

The $P$. aeruginosa PAK strain was introduced to establish a mouse inflammation model. The survival rate was measured $4 \mathrm{~h}, 8 \mathrm{~h}, 12 \mathrm{~h}, 16 \mathrm{~h}, 20 \mathrm{~h}$ and $24 \mathrm{~h}$ after treatment with the $P$. aeruginosa PAK strain. The survival curve of the mice is presented in Figure 1A. Within $24 \mathrm{~h}$ of infection, the survival rate of the mice was only $20 \%$ in the model group, compared to $30 \%, 70 \%$ and $80 \%$ in the low, middle and high dose RM groups, respectively. No death was observed in the positive control group. These results suggest that RM exerts a protective effect against $P$. aeruginosa PAK strain lung infection.

Pathologic sections of lung tissue are presented in Figure 1B. Compared to the structural integrity of the lung tissue from the control group, the lung sections from the model group displayed a widened alveolar septum, capillary congestion, and inflammatory cell infiltration around the plasma vessels. This result indicated that the infection model was successfully established. The inflammatory infiltrates were significantly alleviated in the high dose RM group, with less neutrophil recruitment and reduced histological injury. Histopathological evaluation of inflammation revealed that RM exerted anti-inflammatory effects on the mouse lung infection model.

Furthermore, the levels of the inflammatory cytokines IL-6, IL- 8 and TNF- $\alpha$ in serum samples from the mice were determined via ELISA. As shown in Figure $1 C$, the levels of IL-6, IL- 8 and TNF- $\alpha$ in the model group were significantly higher (more than control) $(p<0.001)$. Compared to the model group, the levels of IL- 6 , IL- 8 and TNF- $\alpha$ were significantly decreased in both the middle and high dose RM groups $(p<0.001$ in TNF- $\alpha, p<0.01$ in IL- 6 and IL- 8 of RM-H, $p<0.01$ in TNF- $\alpha, p<0.05$ in IL-6 of RM-M). These results demonstrated that RM treatment 

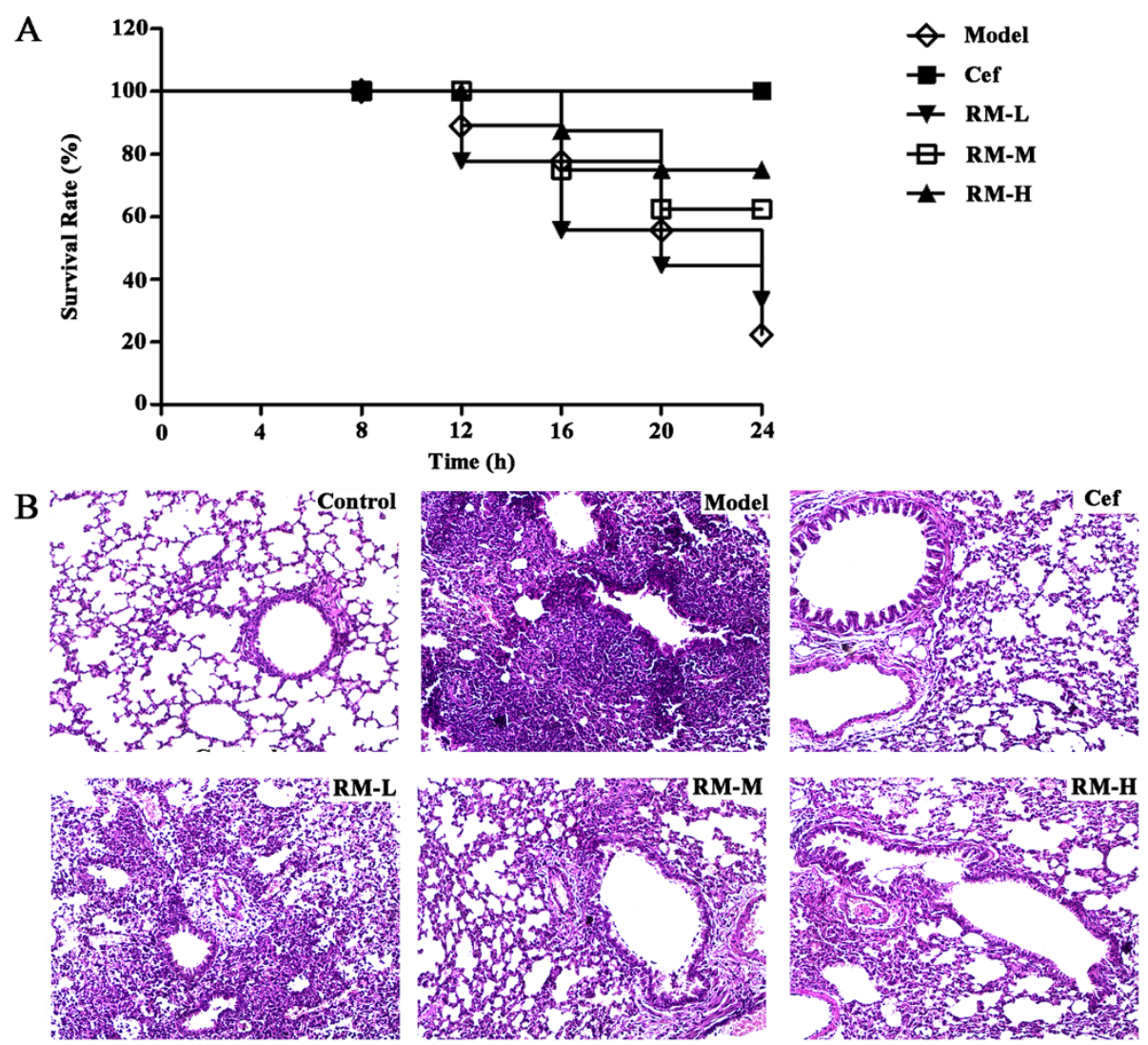

C

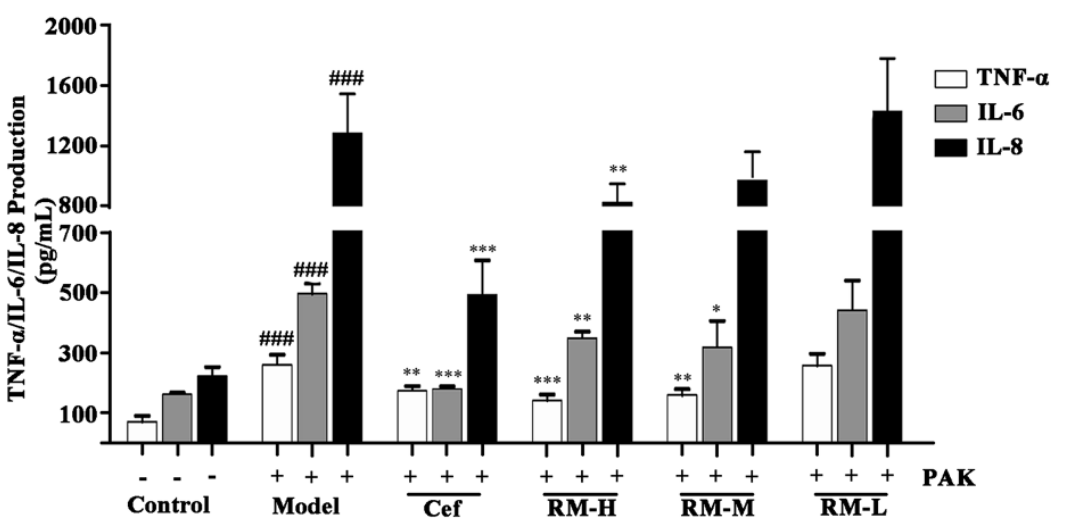

Figure 1 Effect of RM on lung infection induced by the $P$. aeruginosa PAK strain. (A) The survival rate of mice treated with RM or Cef upon challenge with P. aeruginosa. The survival rate was assessed for 24 h; (B) lung tissue pathology slices (the light microscopic images were captured at 100× magnification); (Control) control group, (Model) model group, (Cef) positive control group, (RM-H) high dose RM group, (RM-M) middle dose RM group,(RM-L) low dose RM group. Comparing with the control group, obvious inflammatory cell infiltration in mucosa and submucosa in model group; (C) effects of RM on the production of TNF- $a, \mathrm{IL}-6, \mathrm{IL}-8$ in mouse serum.Value were expressed as the mean $\pm \mathrm{SEM}(n=6)$.

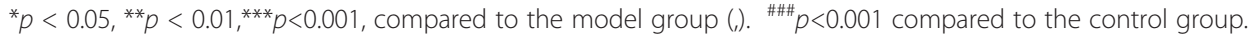

could strongly inhibit the induction of certain inflammatory cytokines by $P$. aeruginosa.

\section{Effects of the BUE of RM on NF-KB activity}

The effects of the different extracts of RM on TNF- $\alpha$ stimulated NF-kB activity in HEK 293 cells are presented in Figure 2. Dex was used as positive control for NF- $\mathrm{kB}$ activity. The crude drug concentration of RM is $100 \mathrm{mg} / \mathrm{mL}$ of the various extracts. As a result, Dex $\left(10^{-5} \mathrm{~mol} / \mathrm{L}\right)$ and the BUE of RM significantly inhibited TNF- $\alpha$-induced NF-kB production (Figure 2), indicating that the BUE extract represents a source of potential NF- $\mathrm{KB}$ inhibitors. Although EAE also weakly inhibited NF- $\mathrm{kB}$ activity, the BUE extract was used for the further identification of RM compounds via UPLC-Q/TOF MS analysis and bioactivity detection due to its greater potential for NF-kB inhibition. 


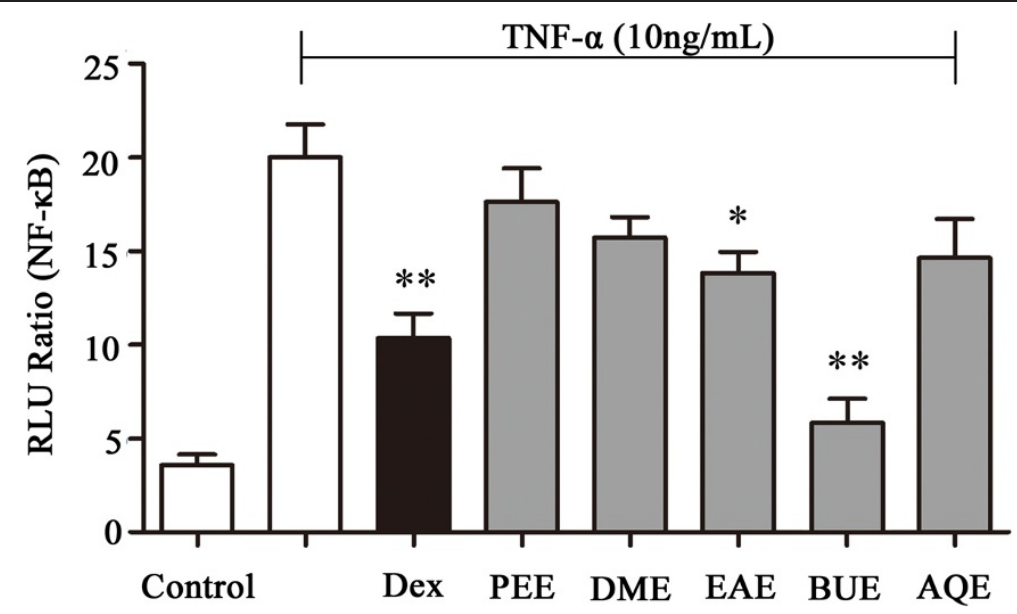

Figure 2 Effects of the five extracts from RM on the level of NF-KB activity in TNF-a-stimulated HEK 293 cells.

UPLC/Q-TOF MS analysis of the BUE of RM

The optimal UPLC/Q-TOF-MS method was performed on the BUE of RM. The column effluent was split 1:9 after substance separation. One part was directed toward QTOF-MS analysis, and the others were directed toward diode array detection. The total ion current chromatograms in the positive ion mode are shown in Figure 3B. $[\mathrm{M}+\mathrm{H}]^{+}$ ions were recorded with as much relevant information as possible to confirm the molecular weight, and the structure of all of the constituents were deduced based on their exact molecular weight, which was compared with the literature data and the natural products information reported in [30]. The MS/MS fragments and the retention time verified the conclusions. Some peaks that had the same protonated molecules in the MS spectra and similar fragment ions in the MS/MS spectra could be distinguished and identified due to their different retention behaviors. In the present study, peak 1 at $2.23 \mathrm{~min}$ was chosen to demonstrate the identification approach that was taken. The base peak in the positive ESI mode was $m / z$ 476.1713, which was confirmed to be the $[\mathrm{M}+\mathrm{H}]^{+}$. The elemental and possible molecular compositions $\left(\mathrm{C}_{24} \mathrm{H}_{29} \mathrm{NO}_{9}\right)$ were deduced based on
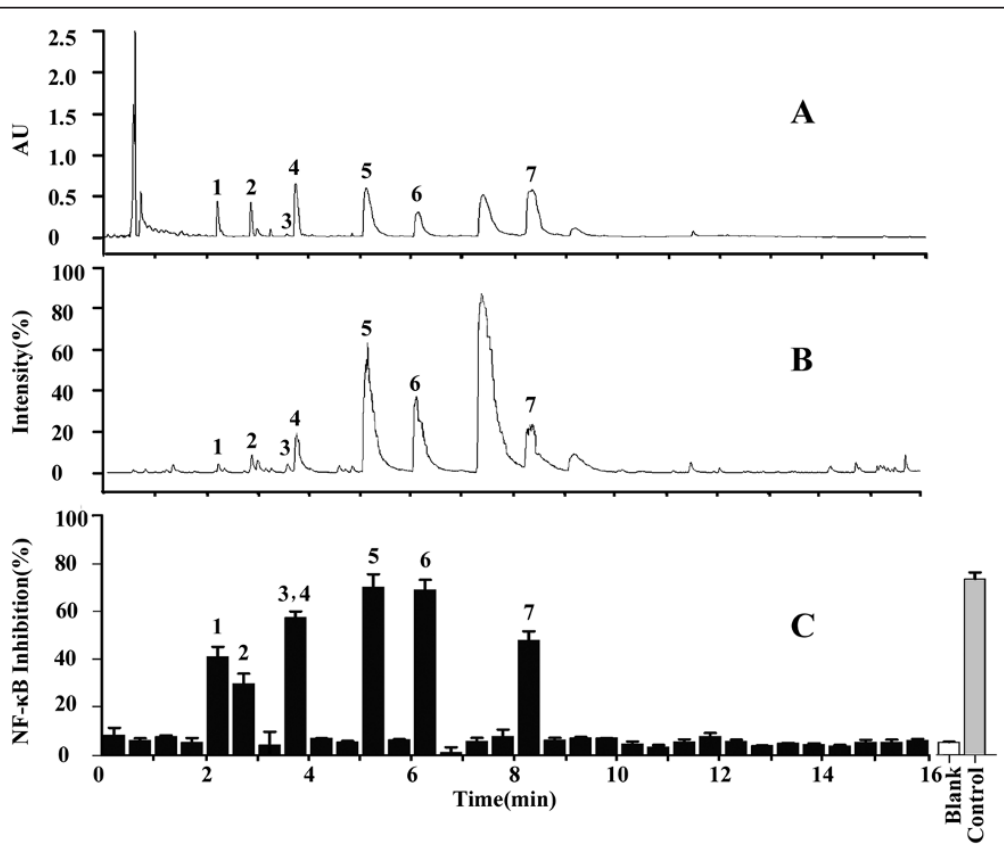

Figure 3 UPLC/Q-TOF MS and bioactivity analysis of the BUE of RM. (A) UPLC/UV chromatograms of the BUE of RM; (B) TIC chromatogram in the positive ESI mode; and (C) the chromatogram of the NF-KB activity detected via the dual-luciferase reporter assay system to determine NF-kB inhibition. The peak values are consistent with those reported in Table 1. 
Table 1 The information about formula, maximum absorption wavelength, retention time, product ions and the identification results for the bioactive compounds in RM

\begin{tabular}{|c|c|c|c|c|c|c|c|}
\hline Peak no. & $t_{\mathrm{R}}(\min )$ & UV $\left(\lambda_{\max }\right)$ & Identification & Composition & MW & Mode & $\mathrm{MS}^{2}$ \\
\hline 1 & 2.23 & 203,283 & $\begin{array}{l}\text { N-norsinoacutin- } \beta-D \\
\text {-glucopyranoside }\end{array}$ & $\mathrm{C}_{24} \mathrm{H}_{29} \mathrm{NO}_{9}$ & 475.1842 & Pos & $\begin{array}{l}476[\mathrm{M}+\mathrm{H}]^{+}, 314\left[\mathrm{M}+\mathrm{H}-\mathrm{C}_{6} \mathrm{H}_{10} \mathrm{O}_{5}\right]^{+}, \\
136\left[\mathrm{M}+\mathrm{H}-\mathrm{C}_{6} \mathrm{H}_{10} \mathrm{O}_{5}-\mathrm{NC}_{6} \mathrm{H}_{12} \mathrm{O}_{5}\right]^{+}\end{array}$ \\
\hline 2 & 2.89 & 201,280 & $\begin{array}{l}\text { 6-O-methyl-laudanosoline -13-O- } \\
\text { glucopyranoside }\end{array}$ & $\mathrm{C}_{24} \mathrm{H}_{31} \mathrm{NO}_{9}$ & 477.1999 & Pos & $\begin{array}{l}478\left[\mathrm{M}+\mathrm{H}^{+}, 316\left[\mathrm{M}+\mathrm{H}-\mathrm{C}_{6} \mathrm{H}_{10} \mathrm{O}_{5}\right]^{+}\right. \\
194\left[\mathrm{M}+\mathrm{H}_{-} \mathrm{C}_{6} \mathrm{H}_{10} \mathrm{O}_{5}-\mathrm{C}_{7} \mathrm{H}_{4} \mathrm{OHOH}\right]^{+}\end{array}$ \\
\hline 3 & 3.60 & 203,251 & sinomenine & $\mathrm{C}_{19} \mathrm{H}_{23} \mathrm{NO}_{4}$ & 329.1627 & Pos & $\begin{array}{l}330[\mathrm{M}+\mathrm{H}]^{+}, 301\left[\mathrm{M}+\mathrm{H}-\mathrm{CH}_{3} \mathrm{~N}\right]^{+} \\
271\left[\mathrm{M}+\mathrm{H}-\mathrm{CH}_{3} \mathrm{~N}-\mathrm{CH}_{2} \mathrm{O}\right]^{+}\end{array}$ \\
\hline 4 & 3.77 & 226,286 & norsinoacutin & $\mathrm{C}_{18} \mathrm{H}_{19} \mathrm{NO}_{4}$ & 313.1314 & Pos & $\begin{array}{l}314[\mathrm{M}+\mathrm{H}]^{+}, 299[\mathrm{M}+\mathrm{H}-\mathrm{NH}]^{+} \\
269\left[\mathrm{M}+\mathrm{H}-\mathrm{NH}-\mathrm{CH}_{2} \mathrm{O}\right]^{+}\end{array}$ \\
\hline 5 & 5.14 & 224,268 & magnoflorine & $\mathrm{C}_{20} \mathrm{H}_{24} \mathrm{NO}_{4}$ & 342.1700 & Pos & $\begin{array}{l}342[\mathrm{M}]^{+}, 297\left[\mathrm{M}-\mathrm{C}_{2} \mathrm{H}_{7} \mathrm{~N}\right]^{+}, 266[\mathrm{M}- \\
\left.\mathrm{C}_{2} \mathrm{H}_{7} \mathrm{~N}-\mathrm{CH}_{2} \mathrm{OH}\right]^{+}\end{array}$ \\
\hline 6 & 6.12 & $227,280,305$ & laurifloline & $\mathrm{C}_{20} \mathrm{H}_{24} \mathrm{NO}_{4}$ & 342.1700 & Pos & $\begin{array}{l}342[\mathrm{M}]^{+}, 314[\mathrm{M}-\mathrm{CO}]^{+}, 269[\mathrm{M}-\mathrm{CO}- \\
\mathrm{C}_{2} \mathrm{H}_{7} \mathrm{~N}^{+}\end{array}$ \\
\hline 7 & 8.39 & $196,232,281$ & dauricinoline & $\mathrm{C}_{37} \mathrm{H}_{42} \mathrm{~N}_{2} \mathrm{O}_{6}$ & 610.3042 & Pos & $\begin{array}{l}611[\mathrm{M}+\mathrm{H}]^{+}, 580\left[\mathrm{M}+\mathrm{H}-\mathrm{CH}_{3} \mathrm{O}\right]^{+}, \\
388\left[\mathrm{M}+\mathrm{H}-\mathrm{CH}_{3} \mathrm{O}-\mathrm{C}_{11} \mathrm{H}_{14} \mathrm{NO}_{2}\right]^{+},\end{array}$ \\
\hline
\end{tabular}

the exact molecular weight, and the molecular compositions that were retrieved from the fragmentation pathways were consistent with the literature [31]. Peak 1 was thus determined to correspond to N-norsinoacutin- $\beta$-D-glucopyranoside. Similarly, based on the fragmentation pathway and high-resolution mass to four decimal places, the other constituents were identified. The detailed results and structures of the seven candidate compounds are presented in Table 1.
Identification on NF-KB inhibitors in the BUE of RM based on bioactivity analysis

Following UPLC/diode array detection analysis (Figure 3A), $90 \%$ of the column effluents were collected as $0.5 \mathrm{~min}$ fractions for the bioactivity assay using the dual-luciferase reporter assay system. Each of the 36 fractions was evaluated for their effect on NF- $\mathrm{kB}$ activity (Figure 3C). Seven candidate compounds (Peaks 1 to 7 ) displayed potential NF- $k B$ inhibition that was two times higher than the blank.

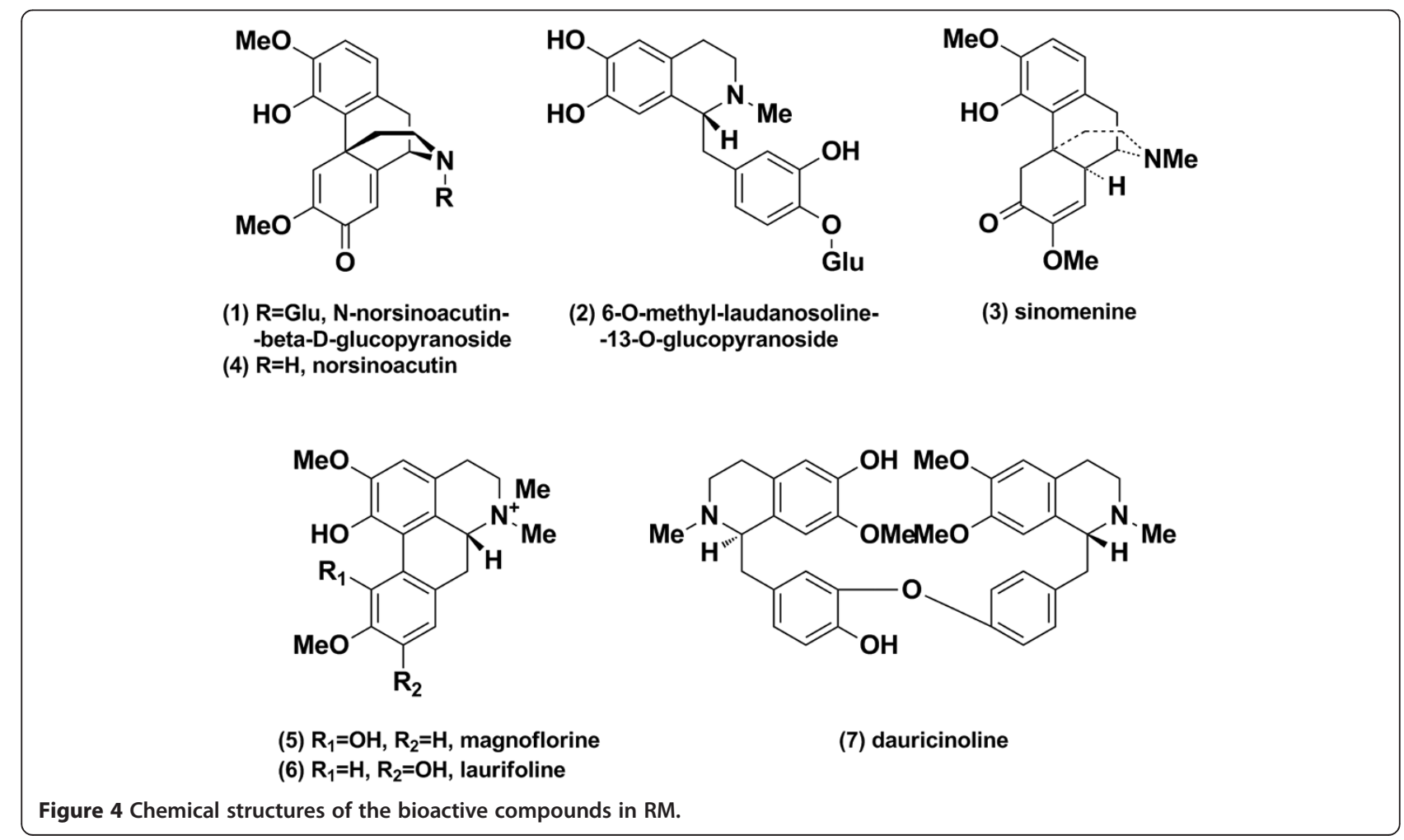




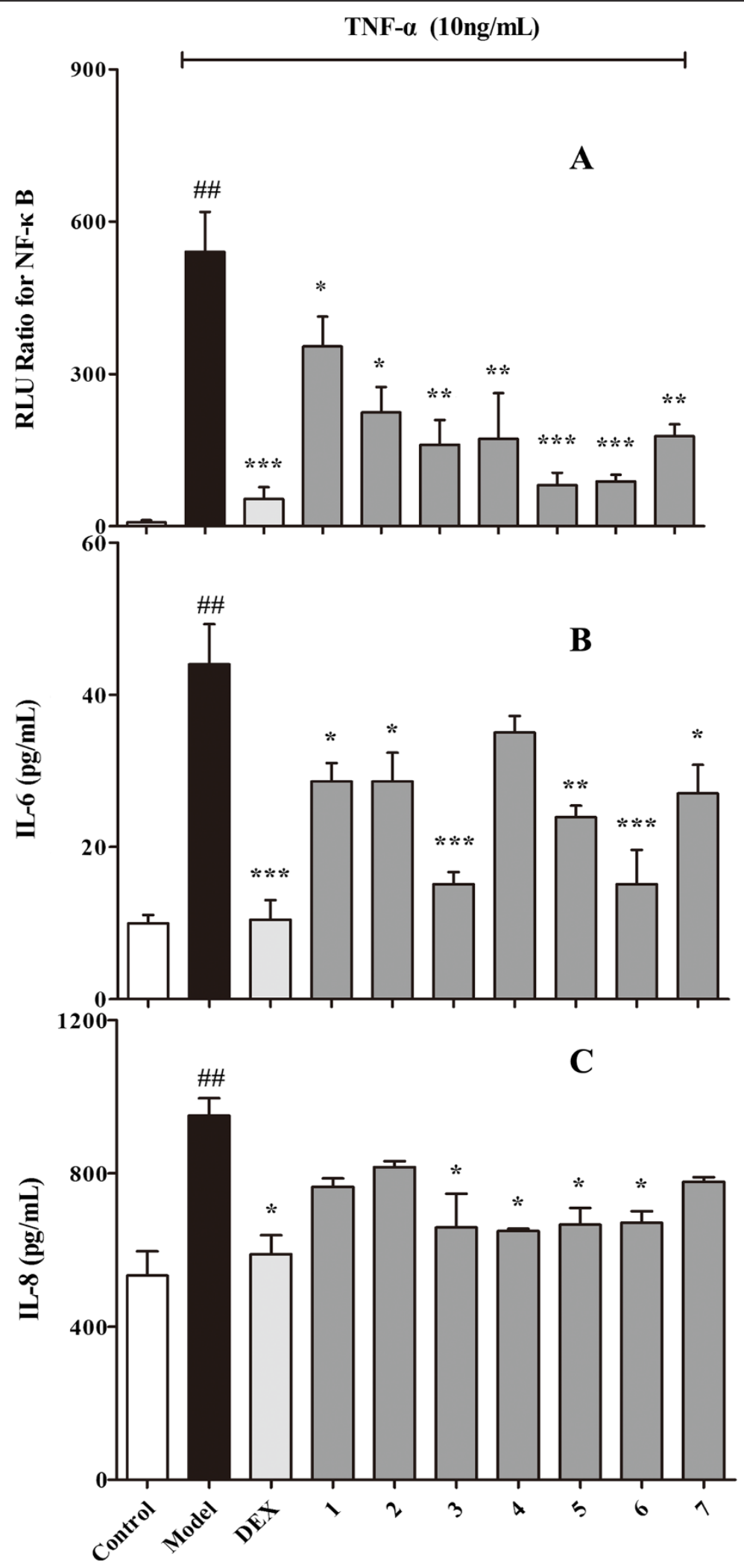

Figure 5 Confirmation of the effects by potential NF-kB inhibitors. A: Effects of the potential NF-kB inhibitors on the NF-kB expression. B and C: IL-6 and IL-8 expression in TNF-a induced BEAS-2B cells, respectively. Each bar represents the mean $+\mathrm{SEM} ; \mathrm{n}=4$ for each group. (1: N-norsinoacutin- $\beta$-Dglucopyranoside; 2: 6-O-methyl-laudanosoline-13-O-glucopyranoside; 3: sinomenine; 4: norsinoacutin; 5: magnoflorine; 6: laurifloline; 7: dauricinoline). ${ }^{*} p<0.05,{ }^{* *} p<0.01,{ }^{* * *} p<0.001$ compared to the model group. ${ }^{\# \#} p<0.01$ compared to the control group. 
The structures of these bioactive compounds in the BUE are presented in Figure 4. The potential NF-kB inhibitors include: sinomenine, norsinoacutin, magnoflorine, $\mathrm{N}$ norsinoacutin- $\beta$-D-glucopyranoside, dauricinoline. laurifloline and 6-O-methyl-laudanosoline-13-O-glucopyranoside, There was a major peak between peaks 6 and 7, which was deduced as menisperine based on UPLC/Q-TOF MS. However, in our study it did not display an inhibitory effect on NF- $\mathrm{kB}$ activity.

\section{Confirmation of the bioactivity of the NF-KB inhibitors in RM}

The activities of the bioactive compounds $(100 \mu \mathrm{mol} / \mathrm{L})$ in RM were evaluated using the dual-luciferase reporter assay system. As shown in Figure 5A, Dex $(10 \mu \mathrm{mol} / \mathrm{L})$ and the seven potential NF- $\mathrm{kB}$ inhibitors (ingredients of $\mathrm{RM}$ ) displayed significant NF-kB inhibitory effects $(p<0.05)$ compared to the model group. Especially, sinomenine, magnoflorine and laurifloline $(p<0.001)$ displayed highly significant inhibition. Because NF- $\mathrm{kB}$ transcription factors synergistically activate transcription of the inflammatory cytokines IL-6 and IL-8, the anti-inflammatory effect of these seven ingredients on IL-6 and IL-8 were further evaluated [32]. As shown in Figure 5B, IL-6 expression was reduced by six of the compounds $(p<0.05)$, highly significantly by laurifloline and sinomenine $(p<0.001)$; however, norsinoacutin displayed no significant IL-6 inhibition based on our assay. For IL-8, as shown in Figure 5C, sinomenine, norsinoacutin, magnoflorine and laurifloline demonstrated an inhibitory effect $(p<0.05)$, but the other three compounds did not display an inhibitory effect. Dex $(10 \mu \mathrm{mol} / \mathrm{L})$, the positive control, significantly inhibited both IL-6 $(p<0.001)$ and IL-8 expression $(p<0.05)$. The results further confirmed the anti-inflammatory effects of the seven compounds as NF- $\mathrm{kB}$ inhibitors in RM.

Previous studies have demonstrated that magnoflorine can increase the phagocytosis of neutrophils at a concentration of $0.5 \mu \mathrm{g} / \mathrm{mL}$ in vitro, suggesting that magnoflorine exerts significant anti-inflammatory effects [33]. Additionally, sinomenine has been used clinically to treat rheumatoid arthritis. A systematic review and meta-analysis revealed that sinomenine treatment can significantly decrease rheumatoid factor levels in patients [34]. IL-6 gene expression is also significantly diminished by treatment with $1 \mathrm{mmol} / \mathrm{L}$ sinomenine for $48 \mathrm{~h}$ based on RT-PCR analysis, suggesting an anti-inflammatory effect of sinomenine [35]. Consistent with a previous report [36], we demonstrated the anti-inflammatory effects of magnoflorine and sinomenine, both of which significantly reduced the expression of IL-6 and IL-8. This study is the first to report that 6-Omethyl-laudanosoline-13-O-glucopyranoside, norsinoacutin, laurifloline, dauricinoline and N-norsinoacutin- $\beta$-D-glucopyranoside inhibit the activation of NF- $\mathrm{kB}$. The NF-kB protein is a transcription factor that enhances the transcription of a variety of genes, including cytokines, growth factors, adhesion molecules and immunoreceptors [37]. Upon activation, I $\mathrm{KB}$ is phosphorylated and degraded, leading to the activation of NF- $\mathrm{KB}$, further increasing the expression of inflammatory cytokines [38,39]. Norsinoacutin did not display significant IL-6 inhibition, and 6-O-methyl-laudanosoline13-O-glucopyranoside, dauricinoline and N-norsinoacutin$\beta$-D-glucopyranoside did not display an inhibitory effect on IL-8 expression in the present study. However, these compounds may act on other cytokines, which require verification in further experiments.

\section{Conclusions}

Our results revealed that RM could contribute to the alleviation of inflammation in mice subjected to acute lung infection induced by the $P$. aeruginosa PAK strain. UPLC-Q/ TOF MS coupled with a luciferase reporter assay was utilized to screen for and identification the NF- $\mathrm{kB}$ inhibitors that may be responsible for the anti-inflammatory effects of RM. Consequently, seven alkaloids were characterized as NF- $\mathrm{kB}$ inhibitors. Among these compounds, to the best of our knowledge, this is the first report that the alkaloids $\mathrm{N}$ norsinoacutin- $\beta$-D-glucopyranoside, 6-O-methyl-laudanosoline-13-O-glucopyranoside, laurifloline, dauricinoline and norsinoacutin interact with NF-kB. Furthermore, IL-6 and IL-8 activity assays confirmed the anti-inflammatory effects of these seven bioactive alkaloids. This study identified the NF- $k B$ inhibitory compounds in RM and provided useful results for further investigation of its anti-inflammatory effects at the molecular level.

\section{Competing interests}

The authors declare that they have no competing interests.

\section{Authors' contributions}

Conceived and designed the experiments: YH, GB. Performed the experiments: DS, MZ, XY, BC, YH, YN. Analyzed the data: DS, MZ, XY. Wrote the paper: DS, YH. All authors read and approved the final manuscript.

\section{Acknowledgements}

This work was supported by a Grant from the National Natural Science Foundation of China (Nos. 81373506; 81102835), the Specialized Research Fund for the Doctor Program of Higher Education of China (Nos. 20120031110042) and the Key Program of Natural Science of Foundation of Tianjin, China (Nos.13JCZDJC31400).

Received: 11 July 2014 Accepted: 19 September 2014 Published: 25 September 2014

References

1. Hai CM: Airway smooth muscle cell as therapeutic target of inflammation. Curr Med Chem 2007, 14(1):67-76.

2. Matthay MA, Zimmerman GA: Acute lung injury and the acute respiratory distress syndrome - four decades of inquiry into pathogenesis and rational management. Am J Resp Cell Mol 2005, 33(4):319-327.

3. Bismarck PV, Winoto MS, Herzberg M, Uhlig U, Schuetze S, Lucius R, Krause MF: IKK NBD peptide inhibits LPS induced pulmonary inflammation and alters sphingolipid metabolism in a murine model. Pul Pharmacol \& Ther 2012, 25(3):228-235.

4. Li QT, Verma IM: NF-kappa B regulation in the immune system. Nat Rev Immunol 2002, 2(10):725-734 
5. Hoesel B, Schmid JA: The complexity of NF-kappa B signaling in inflammation and cancer. Mol Cancer 2013, 12:86-101.

6. Baldwin AS: Series introduction: the transcription factor NF-kappa B and human disease. J Clin Invest 2001, 107(1):3-6.

7. Sun Z, Andersson R: NF-kB activation and inhibition: a review. Shock 2002, 18(2):99-106.

8. Petrova RD, Reznick AZ, Wasser SP, Denchev CM, Nevo E, Mahajna J: Fungal metabolites modulating NF-kappa B activity: an approach to cancer therapy and chemoprevention (Review). Oncol Rep 2008, 19(2):299-308.

9. Wang Q, Kuang H, Su Y, Sun Y, Feng J, Guo R, Chan K: Naturally derived anti-inflammatory compounds from Chinese medicinal plants. J Ethnopharmacol 2013, 146(1):9-39.

10. Drayton DL, Liao S, Mounzer RH, Ruddle NH: Lymphoid organ development: from ontogeny to neogenesis. Nat Immunol 2006, 7(4):344-353.

11. Spco C: Pharmacopoeia of the people's Republic of China. Beijing: Chinese medical science and technology press; 2010.

12. Bao GH, Qin GW, Wang R, Tang XC: Morphinane alkaloids with cell protective effects from Sinomenium acutum. J Nat Prod 2005, 68(7):1128-1130.

13. Jin $H Z$, Wang $X L$, Wang $H B$, Wang $Y B$, Lin LP, Ding J, Qin GW: Morphinane alkaloid dimers from Sinomenium acutum. J Nat Prod 2008, 71(1):127-129.

14. Min YD, Choi SU, Lee KR: Aporphine alkaloids and their reversal activity of multidrug resistance (MDR) from the stems and rhizomes of Sinomenium acutum. Arch Pharm Res 2006, 29(8):627-632.

15. Sugimoto Y, Matsui M, Takikawa H, Sasaki M, Kato M: Dechlorodauricumine from cultured roots of Menispermum dauricum. Phytochemistry 2005, 66(22):2627-2631.

16. Zheng $L N$, Luo $D$, Sun $R$ : The margin of safety study on anti-inflammatory effect of different components from Rhizoma Menispermi. Chin J Pharmacovigilance 2012, 9(6):335-337.

17. Liu X, Han F: Anti-inflammatory effect and acute toxicity of Menispermum Dauricum. Heilongijiang Med J 2000, 13(2):98-99.

18. Hou YY, Cao XL, Dong LY, Wang LQ, Cheng BF, Shi Q, Luo XD, Bai G Bioactivity-based liquid chromatography-coupled electrospray ionization tandem ion trap/time of flight mass spectrometry for $\beta 2 A R$ agonist identification in alkaloidal extract of Alstonia scholaris. $J$ Chromatogr A 2012, 1227:203-209.

19. Li L, Luo GA, Liang QL, Hu P, Wang YM: Rapid qualitative and quantitative analyses of Asian ginseng in adulterated American ginseng preparations by UPLC/Q-TOF-MS. J Pharmaceut Biomed 2010, 52(1):66-72.

20. Cheng BF, Hou YY, Wang LQ, Dong LY, Peng JM, Bai G: Dual-bioactivitybased liquid chromatography-coupled quadrupole time-of-flight mass spectrometry for NF-KB inhibitors and $\beta 2 A R$ agonists identification in Chinese Medicinal Preparation Qingfei Xiaoyan Wan. Anal Bioanall Chem 2012, 404(8):2445-2452.

21. Bai F, Xu HJ, Zhang Q, Qi XZ, Mou R, Bai G, Qiao MQ: Functional characterization of pfm in protein secretion and lung infection of Pseudomonas aeruginosa. Canadian J Microbiol 2011, 57(10):829-837.

22. Mulcahy LR, Isabella VM, Lewi K: Pseudomonas aeruginosa biofilm Potential therapeutic targets. Microb Ecol 2014, 68:1-12.

23. Fazli M, Almblad H, Rybtke ML, Givskov M, Eberl L, Tolker NT: Regulation of biofilm formation in Pseudomonas and Burkholderiaspecies. Environ Microbiol 2014, 16(7):1961-1981

24. Sharma G, Rao S, Bansal A, Dang S, Gupta S, Gabrani R: Pseudomonas aeruginosa biofilm: potential therapeutic targets. Biologicals 2014, 42(1):1-7.

25. Sun HY, Fujitani S, Quintiliani R, Yu VL: Pneumonia due to pseudomonas aeruginosa part ii: antimicrobial resistance, pharmacodynamic concepts, and antibiotic therapy. Chest 2011, 139(5):1172-1185.

26. Talbot GH, Bradley J, Edwards JE, Gilbert D, Scheld M, Bartlett JG: Bad bugs need drugs: an update on the development pipeline from the Antimicrobial Availability Task Force of the Infectious Diseases Society of America. Clin Infect Dis 2006, 42(5):657-668.

27. Barnes PJ: Pathophysiology of allergic inflammation. Immunol Rev 2011, 242:31-50.

28. VanReeth K: Cytokines in the pathogenesis of influenza. Vet Microbiol 2000, 74(1-2):109-116.

29. Shan ZY, Xu HJ, Shi XQ, Yu Y, Yao HM, Zhang XM, Bai YL, Gao GC, Saris PEJ, Qiao MQ: Identification of two new genes involved in twitching motility in Pseudomonas aeruginosa. Microbiol-SGM 2004, 150:2653-2661.

30. Zhou J, Xie G, Yan X: Chemical component of source plants in tranditional Chinese medicine. Beijing: Science Press; 2009.
31. Yi L, Liang ZT, Peng $Y$, Yao $X$, Chen HB, Zhao ZZ: Tissue-specific metabolite profiling of alkaloids in Sinomenii Caulis using laser microdissection and liquid chromatography-quadrupole/time of flight-mass spectrometry. J Chromatogr A 2012, 1248:93-103.

32. Ciarcia R, Vitiello MT, Galdiero M, Pacilio C, lovane V, D'Angelo D, Pagnini D, Caparrotti G, Conti D, Tomei V: Imatinib treatment inhibit IL-6, IL-8, NF-KB and AP-1 production and modulate intracellular calcium in CML patients. J Cell Physiol 2012, 227(6):2798-2803.

33. Sharma U, Bala M, Kumar N, Singh B, Munshi RK, Bhalerao S: Immunomodulatory active compounds from Tinospora cordifolia. J Ethnopharmacol 2012, 141(3):918-926.

34. Xu M, Liu L, Qi C, Deng B, Cai X: Sinomenine versus NSAIDs for the treatment of rheumatoid arthritis: a systematic review and metaanalysis. Planta Med 2008, 74(12):1423-1429.

35. Li XJ, Yue PYK, Ha WY, Wong DYL, Tin MMY, Wang PX, Wong RNS, Liu L: Effect of sinomenine on gene expression of the IL-1 $\beta$-activated human synovial sarcoma. Life Sci 2006, 79(7):665-673.

36. Kim BR, Seo HS, Ku JM, Kim GJ, Jeon C, Park J, Jang BH, Park SJ, Shin YC, Ko SG: Silibinin inhibits the production of pro-inflammatory cytokines through inhibition of NF-KB signaling pathway in HMC-1 human mast cells. Inflamm Res 2013, 62(11):941-950.

37. Blackwell TS, Blackwell TR, Christman JW: Induction of endotoxin tolerance depletes nuclear factor-kappaB and suppresses its activation in rat alveolar macrophages. J Leukocyte Biol 1997, 62(6):885-891.

38. Baeuerle PA, Baltimore D: NF-kB: ten years after. Cell 1996, 87(1):13-20.

39. Mercurio F, Manning AM: Multiple signals converging on NF-KB. Curr Opin Cell Biol 1999, 11(2):226-232.

\section{doi:10.1186/1472-6882-14-356}

Cite this article as: Sun et al.: Identification of nuclear factor-KB inhibitors in the folk herb Rhizoma Menispermi via bioactivity-based ultra-performance liquid chromatography/quadrupole time-of-flight mass spectrometry analysis. BMC Complementary and Alternative Medicine 2014 14:356.

\section{Submit your next manuscript to BioMed Central and take full advantage of:}

- Convenient online submission

- Thorough peer review

- No space constraints or color figure charges

- Immediate publication on acceptance

- Inclusion in PubMed, CAS, Scopus and Google Scholar

- Research which is freely available for redistribution

Submit your manuscript at www.biomedcentral.com/submit
C Biomed Central 